http://jmscr.igmpublication.org/home/

ISSN (e)-2347-176x ISSN (p) 2455-0450

crossref DOI: https://dx.doi.org/10.18535/jmscr/v7i7.72

\title{
A Comparative Study: Haemodynamic Changes in Paediatric Laparoscopic Surgery
}

\author{
Authors

\section{Dr H N Madhusudana, Dr Aditya Sapra, Dr A B Tiwari*, Dr Nikhil Mestha}

Dept of Anaesthesiology, Air Force Hospital, Kanpur, India: 208004

*Corresponding Author

Dr A B Tiwari

Dept of Anaesthesiology, Air Force Hospital, Kanpur, India 208004

\begin{abstract}
The paediatric laparoscopic surgery has gained popularity due to reduced morbidity, mortality and health care costs. However, the intra-abdominal pressure (IAP) and higher vagal tone are critical determinants of cardiovascular stability and its anaesthetic management during laparoscopy. Paediatric laparoscopic procedures are likely to cause an increase in pulmonary and systemic vascular resistance, sudden bradycardia during pneumoperitoneum because peritoneal stimulation by a blast of insufflated gas or penetration by trocars and laparoscopes. The present study was designed to quantify the changes in haemodynamics and compare these with conventional abdominal surgery.

Keywords and Abbreviation: Oxygen Saturation, Intra-abdominal pressure, Systemic vascular resistance, Cardiac index, End tidal carbon-dioxide, Partial pressure of venous carbon-dioxide.
\end{abstract}

\section{Introduction}

The earliest reference to laparoscopy dates back to Biblical history. In 1901, George Kelling used a cystoscope to examine the intra-abdominal viscera of a dog after insufflating the peritoneal cavity with air, and coined the term "celioscopy. He was one of the earliest advocates of minimally invasive surgery and reported his 22 years of experience with laparoscopy to the German Surgical Society in 1923. ${ }^{[1,2]}$

Since, the introduction of minimal access surgery, paediatric laparoscopy byKelling in 1923 and the first human laparoscopic cholecystectomy by Phillipe Mouret in 1987, laparoscopic cholecystectomy has become prevalent worldwide. The first case of laparoscopy in paediatric surgery was reported by Stephen Gans in 1971, in his landmark publication, "Advances in Endoscopy of Infants and Children," as peritoneoscopy. ${ }^{[3]}$

A laparoscopic approach offers several advantages; potentially reduces the surgical stress, fluid shifts, less need for postoperative analgesia, reduction of postoperative respiratory and wound complications; shortens postoperative convalescence, rapid return to normal diet and decreased overall hospital stay, smaller surgical scars and better maintenance of homeostasis. ${ }^{[4]}$

The hallmark of laparoscopy is creation of carbon dioxide pneumo-peritoneum. Though laparoscopic surgery offers many benefits over conventional surgery, it still has several systemic effects. The cardiovascular effects are increase in pulmonary and systemic vascular resistance, sudden 
bradycardia during pneumoperitoneum with a blast of insufflated gas or penetration by trocars and laparoscopes and even by raised intraabdominal pressure (IAP). ${ }^{[5]}$ Thus limiting the IAP to $6 \mathrm{mmhg}$ in infants and to $12 \mathrm{mmHg}$ in older children has been found to have minimal effects on cardiac index. ${ }^{[6]}$ The pulmonary effects can lead to significant ventilation perfusion mismatch as a consequence of reduced diaphragmatic excursion, reduced thoracic compliance \& functional residual capacity; early closure of smaller airways \& increased peak airway pressures. The other potential threats are endobronchial intubation, subcutaneous emphysema, pneumothorax, pneumomediastinum, massive $\mathrm{CO}_{2}$ embolism, bronchospasm, bronchial hypersecretion and atelectasis. ${ }^{[7]}$ There are effects on other systems such as rise in ICP and CBF, risk of regurgitation, venous stasis, reduction in splanchnic, hepatic, and renal blood flow, oliguria, metabolic acidosis and increase in the plasma concentrations of catecholamines, cortisol, insulin, epinephrine, prolactin, growth hormone, and glucose levels. ${ }^{[8]}$

The surgical concerns are intra-abdominal pressure and crowding of viscera small space, which is decided according to the age group of patients. It leads to restricted access of periumbilical area for port because of risk of umbilical vessels, stomach and bladder puncture. It needsdeflation to reduce the risk of visceral injury. ${ }^{[8,9]}$

Though there is adequate data on anaesthesia for laparoscopic surgery in adults it is inappropriate to extrapolate data obtained in adult laparoscopy to children, as children are not small adults. There is paucity of published data on anaesthesia for minimally invasive surgery in young population. Existing reports mostly vary from anecdotal to small observational studies.

There are few controlled studies onlaparoscopic appendectomy and fundoplication in children, these have helped to identify the benefits and drawbacks of this technique ${ }^{[10,11]}$. The present study was designed to quantify the haemodynamics, $\mathrm{pH}$ and partial pressure of venous carbon dioxide changes in paediatric patients undergoing laparoscopic surgery and to compare these with conventional abdominal surgery in children.

\section{Material \& Method}

After permission from Hospital Ethics Committee and written informed consent,60 paediatric patients undergoing elective abdominal surgery under general anaesthesia in ASA Grade I / II, aged below 05 years weighing less than $20 \mathrm{~kg}$, were enrolled in study. They were randomly divided into 2 groups of 30 patients each, the Group I: Consisted of patients taken up for abdominal laparoscopic surgery while Group II: Consisted of patients taken up for conventional abdominal surgery.The patients were permitted milk and solids up to $6 \mathrm{hrs}$ and clear fluids up to 4 hrs before surgery. $20 \mathrm{ml} / \mathrm{kg} \mathrm{N} / 3$ glucose saline solution was administered to all patients, to offset haemodynamic effects during induction.

All children in both groups were premedicated with midazolam $0.10 \mathrm{mg} / \mathrm{kg}$ intravenous 30 minutes before starting surgery. Premedicated with fentanyl $2 \mu \mathrm{g} / \mathrm{kg}$. General anaesthesia (GA) was induced with propofol $2.0-2.5 \mathrm{mg} / \mathrm{kg}$ and endotracheal intubation was facilitated with vecuronium $0.1 \mathrm{mg} / \mathrm{kg}$ with an appropriate size of an endotracheal tube. GA was maintained with an oxygen, nitrous oxide, and sevoflurane $(0.8 \%-1.2 \%)$, supplemented with fentanyl $0.5-1.0 \mu \mathrm{g} / \mathrm{kg}$ and vecuronium boluses at appropriate intervals.Patients were mechanically ventilated using oxygen and nitrous oxide with tidal volume of $10 \mathrm{ml} / \mathrm{kg}$, an i:e ratio of $1: 2$ and respiratory rate $(\mathrm{RR})$ was adjusted initially to maintain end-tidal $\mathrm{CO}_{2}$ below $30-35 \mathrm{mmHg}$ and limiting the peak airway pressure to $30 \mathrm{cmH}_{2} \mathrm{O}$.In Group I, $\mathrm{CO}_{2}$ was used for pneumoperitoneum, the intra-abdominal pressure exerted by $\mathrm{CO}_{2}$ was kept $<10-12 \mathrm{~cm} \mathrm{H}_{2} \mathrm{O}$. All patients were monitored with pulse oximetry, basal heart rate, blood pressure (automated NIBP), temperature, 
continuous ECG, $\mathrm{EtCO}_{2}$, airway pressure, $\mathrm{pH}$ of blood and $\mathrm{PvCO}_{2}$ of bloodin both the groups of patients intermittently recorded at induction, intubation, starting surgery, half hourly intervals, at end of surgery and post-operatively.

The statistical analysis was done using SPSS (Statistical Package for Social Sciences) for Windows, Version 16.0. Chicago, SPSS Inc. Data variables were expressed as mean \pm standard deviation. Student's t-test and Chi-square test were applied to compare different variables between the two groups. $\mathrm{P}<0.05$ was considered statistically significant.

\section{Result}

A total of 60 patients of ASA Grade I and II included in the study were divided in two equal groups. The demographic distribution of patients for age, height, weight gender and nature of surgery was statistically analysed and found identical. (Table 1). The baseline recording of hemodynamic variables i.e. heart rate, $\mathrm{SpO}_{2}$, systolic blood pressure, diastolic blood pressure, $\mathrm{EtCO}_{2}, \mathrm{PvCO}_{2}$ and peak inspiratory pressure (PIP) $\mathrm{cm} \mathrm{H}_{2} \mathrm{O}$ of Group I and Group II was statistically not significant $(\mathrm{p}>0.05)$ (Table 2). All patients were monitored with pulse oximetry, basal heart rate, blood pressure (SBP and DBP), temperature, continuous ECG, EtCO2, $\mathrm{PvCO}_{2}$ andpeak airway pressure at induction, intubation, starting surgery, at half hour interval, at end of surgery and postoperatively. The anaesthesia technique remained identical in all the cases. The maximum number of cases in both the groups consisted congenital hernia and undescended testis and surgeries were completed within 60 minutes, while few took more than 60 minutes. However all of them were completed surgeries in less than 120 minutes.

The intergroup comparison of arterial oxygen saturation, Heart rate and systolic and diastolic blood pressure, were identical and their difference was statistically not significant. The end tidal concentration of carbon dioxide gradually increased in group I, following pneumoperitoneum. The rise in $\mathrm{EtCO}_{2}$ concentration was evident at all stages of following creation of pneumo-peritoneum, though it was a marginal rise but statistically significant. ( $\mathrm{p}$-value $<0.05$ ). The arterial blood gas analysis of intergroup comparison reciprocated the rise of $\mathrm{EtCO}_{2}$, i.e. comparatively there was a significant fall in $\mathrm{pH}$ in Group I (p-value< 0.05) following pneumoperitoneum.However toward the end of surgery and during post-operative period there was a fall in $\mathrm{pH}$ in Group I but statistically not significant.

The rise in mixed venous partial pressure of carbon dioxide (PvCO2) was nearly about 5-6 mm $\mathrm{Hg}$ from the time $\mathrm{CO} 2$ insufflation, which remained till end of surgery. In group II patients, the $\mathrm{PvCO} 2$ was not raised. The $\mathrm{PvCO}_{2}$ was normal at basal, induction and at intubation levels and showed a gradual rise in Group I, withcreation of pneumo-peritoneum, statistically a significant change but towards the post-operative period it declined. Though the $\mathrm{PvCO}_{2}$ value was higher in Group I but statically not significant. The peak inspiratory pressure remained identical in in either group and the change in PIP was statistically not significant.

Table 1 Demography \& Surgical Data

\begin{tabular}{|c|c|c|c|}
\hline \multicolumn{2}{|c|}{ Demographic Profiles } & Group I $(n=30)$ & Group II $(n=30)$ \\
\hline \multicolumn{2}{|l|}{ Age } & $2.54 \pm 1.44$ & $2.65 \pm 1.52$ \\
\hline \multirow{2}{*}{ Sex } & Male & $20(66.3 \%)$ & $21(70 \%)$ \\
\hline & Female & $10(34.6 \%)$ & $9(30 \%)$ \\
\hline \multicolumn{2}{|l|}{ Weight } & $11.62 \pm 4.10$ & $11.08 \pm 3.92$ \\
\hline \multirow{4}{*}{ Surgery Performed } & Herniotomy & 15 & 13 \\
\hline & Orchidopexy & 11 & 14 \\
\hline & Nephrectomy & 02 & 02 \\
\hline & Splenectomy & 02 & 01 \\
\hline
\end{tabular}


Table 2 Mean Basal Vital Parameters

\begin{tabular}{|l|c|c|c|}
\hline Vital Parameters & Group I $(\mathbf{n = 3 0})$ & Group II $(\mathbf{n}=\mathbf{3 0})$ & p-value \\
\hline Heart Rate & $106.30+13.09$ & $107.63+12.96$ & 0.850 \\
\hline Systolic blood pressure & $116.90 \pm 12.254$ & $115.23 \pm 13.351$ & 0.616 \\
\hline Diastolic Blood Pressure & $62.67 \pm 11.66$ & $61.80 \pm 6.20$ & 0.790 \\
\hline Arterial Oxygen Saturation & $99.57 \pm 0.504$ & $99.53 \pm 0.507$ & 0.797 \\
\hline End tidal concentration $\left(\mathrm{EtCO}_{2}\right)$ & $29.76 \pm 1.179$ & $29.80 \pm 1.182$ & 0.486 \\
\hline $\mathrm{pH}$ of blood & $7.376 \pm 0.030$ & $7.380 \pm 0.014$ & 0.491 \\
\hline $\mathrm{PvCO}_{2}$ of blood & $35.373 \pm 0.020$ & $35.378 \pm 0.012$ & 0.265 \\
\hline $\mathrm{PIP} \mathrm{cm} \mathrm{H}_{2} \mathrm{O}$ & $18.50 \pm 1.121$ & $18.49 \pm 1.098$ & 0.972 \\
\hline
\end{tabular}

Table 3 Peri-operative Vital Parameters

\begin{tabular}{|l|c|c|c|c|c|c|c|c|}
\hline & \multicolumn{8}{|c|}{ Parameters (p-value) } \\
\hline Time Interval & $\mathbf{S p O}_{2}$ & Heart & \multicolumn{2}{|c|}{ Blood Pressure } & EtCO2 & pH & PvCO $_{2}$ & PIP \\
\cline { 4 - 7 } & & Rate & SBP & DBP & & & & \\
\hline Induction & 0.608 & 0.294 & 0.742 & 0.371 & 0.001 & 0.422 & 0.236 & 0.234 \\
\hline Intubation & 0.605 & 0.338 & 0.950 & 0.504 & 0.001 & 0.265 & 0.491 & 0.346 \\
\hline Start of surgery & 1.000 & 0.567 & 0.912 & 0.415 & 0.001 & 0.001 & 0.001 & 0.453 \\
\hline At 30 min & 0.609 & 0.851 & 0.321 & 0.526 & 0.001 & 0.001 & 0.001 & 0.652 \\
\hline End of surgery & 0.608 & 0.717 & 0.732 & 0.687 & 0.001 & 0.006 & 0.001 & 0.622 \\
\hline Post-operatively & 1.000 & 0.899 & 0.605 & 0.660 & 0.001 & 0.745 & 0.082 & 0.784 \\
\hline
\end{tabular}

\section{Discssion}

Laparoscopy in the paediatric population is now a known entity due to its many fold advantages of a minimal access surgery.The great majority of surgical procedures in infants and young children, are now being safely and effectively done using the laparoscope. ${ }^{[4]}$ However, laparoscopy is associated with its own limitations in paediatric patients, owing to crowding of viscera in small space, restricted access of periumbilical area for port, hemodynamic alterations, raised intraabdominal pressure and an alteration in arterial blood gas following absorption of carbon dioxide and circulatory pressure changes. ${ }^{[12]}$

This was an observational comparative study involving two groups of paediatric patients undergoing elective abdominal surgery either laparoscopically or by a conventional open abdominal approach. The study focused on observing changes in heart rate, blood pressure, end tidal carbon-di-oxide, $\mathrm{PvCO} 2$ and $\mathrm{pH}$ during the intra-operative period. Patients were similar in both groups in terms of age, sex, weight, type of surgical pathology and the surgical treatment. The only difference was in the surgical approach, in that, Group I had all the surgeries performed laparoscopically while Group II had all surgeries performed by a non-laparoscopic conventional technique. The observations showed that there was no significant difference in the two groups with respect to heart rate, blood pressure and $\mathrm{SpO}$ 2. Statistically significant differences were there between the groups with regard to Et $\mathrm{CO} 2$, $\mathrm{PvCO} 2$ and $\mathrm{pH}$. However, with judicious changes in the Peak Inspiratory Pressure (PIP), defined in the methodology, these parameters were maintained within the physiological range and did not have any clinical consequence.

Supine position and increase in intra-abdominal pressure in laparoscopic surgery results in decreased venous return and a fall in cardiac output. ${ }^{[13]}$ However there was no demonstrable significant alteration in haemodynamics in present study. The noteworthy point of difference could be a restriction of intra-abdominal pressure to less than $12 \mathrm{~mm} \mathrm{Hg}$ compared to earlier study where intra-abdominal pressure was $15 \mathrm{~mm} \mathrm{Hg}$ and higher ${ }^{[14]}$.Sfez et al in their study on children undergoing laparoscopic fundoplication in supine position with intra-abdominal pressure maintained between $6-10 \mathrm{~mm}$ of $\mathrm{Hg}$, have reported a similar lack of haemodynamic response. ${ }^{[15]}$

There are conflicting reports on effects of pneumo-peritoneum on cardiac index. Joris et 
aldemonstrated a significant decrease in cardiac index when intra-abdominal pressure was raised above $20 \mathrm{~mm}$ of $\mathrm{Hg}^{[16]}$. These results could not be replicated in a similar study by Odeberget al, when intra-abdominal pressure was not as high. ${ }^{[17]}$ However in this study cardiac index was not recorded but the results propose a hypothesis that not much change in cardiac index would be expected if intra-abdominal pressures are kept below $12 \mathrm{~mm} \mathrm{Hg}$ in patients undergoing laparoscopic surgery.

There was no statistical difference between the groups with regard to heart rate and blood pressure changes despite the fact that most surgeries were performed in supine position and all surgeries in Group I involved creation of pneumo-peritoneum and rise in abdominal pressure. This minimal haemodynamic response, especially in the laparoscopic group can be attributed to the fact that in none of the patients, intra-abdominal pressure was raised beyond 12 $\mathrm{mm}$ of $\mathrm{Hg}$. In view of the above, it can be concluded that in paediatric patients undergoing laparoscopic surgery heart rate and blood pressure changes are minimal if the intra-abdominal pressure is kept below $12 \mathrm{~mm} \mathrm{Hg}$. This is in agreement with the studies of Ishizaki $\mathrm{Y}$ et al and Dexter SP et al, who proposed a threshold of 12 $\mathrm{mm} \quad \mathrm{Hg}$ IAP above which significant haemodynamic changes occur. ${ }^{[18,19]}$ Cardiac output in children is depends more on preload and contractility rather than on afterload. All our patients were given fluid preload prior to introduction of pneumo-peritoneum thus counter balancing the reduction in decrease in venous return and consequent reduction in preload.

Most of the surgical procedures in Group I and II were completed in 30 to $60 \mathrm{~min}$. As opposed to Group II, all patients in Group I had $\mathrm{CO} 2$ insufflation but the period for which pneumoperitoneum was maintained was short and did not result in $\mathrm{CO} 2$ absorption related haemodynamic changes, as at no stage did the EtCO2 or the $\mathrm{PvCO} 2$ rise above the physiological range. Bozkurt $\mathrm{P}$ et al also had similar observations that no significant change in $\mathrm{PaCO} 2$ occurred if duration of pneumoperitoneum was shorter than $30 \mathrm{~min}^{[5]}$.

It was observed a fall of $\mathrm{pH}$ along with a rise in EtCO2 and a corresponding rise in $\mathrm{PvCO} 2$ in Group I patients where carbon dioxide insufflation was done. As opposed to this, Group II showed a near constant $\mathrm{pH}$ with minimal changes noted in EtCO2 and $\mathrm{PvCO} 2$. This was in consistent with the animal model study of Sumpe lmann et al. ${ }^{[20]}$ There was no statistically significant difference in the baseline respiratory rate of the two groups. The difference in post-operative respiratory rates, between the two groups, was statistically significant. Respiratory rate was higher in group I, as compared to group II patients, possibly due to the fact that absorbed $\mathrm{CO} 2$ in group I required a wash-out time, where in central respiratory centre was activated.

\section{Conclusion}

On the basis of above observations, it can be concluded that in paediatric patients undergoing laparoscopic surgery, haemodynamic changes (heart rate, systolic and diastolic blood pressure) are offset by maintaining intra-abdominal pressure to less than $12 \mathrm{~cm} \mathrm{H} 2 \mathrm{O}$ during pneumoperitoneum and by optimal intravenous hydration to ensure adequate venous return during pneumoperitoneum.

Respiratory parameters like oxygen saturation, end-tidal carbon dioxide, partial pressure of carbon dioxide in venous blood and $\mathrm{pH}$ can be maintained within physiological limits, by judicious increase of peak inspiratory pressure to about 5-8 $\mathrm{cm} \mathrm{H} 2 \mathrm{O}$, during pneumo-peritoneum. The maintenance of these parameters, within the physiological range, prevents clinical changes in haemodynamics due to hypercarbia and acidosis.

\section{References}

1. Kelling G: ZurCoelioskopie. Arch KlinChir 1923; 126: 226-229.

2. SA Sgambati\& GH Ballantyne. Minimally Invasive Surgery for diseases of the colon 
\& rectum: the legacy of an ancient tradition. In: Rama M. Jager, M.D. , Ph.D. \& Steven Wexner, M.D. Laparoscopic Colectomy, Churchill \& Livingstone. New York. 1995. Pp 13-23.

3. SL Gans, G Berci. Peritoneoscopy in Infants and Children. Journal of Pediatric. Surgery.1973:8(3):399-405 [PubMed] PMID: 4268498

http://dx.doi.org/10.1016/0022-

3468(73)90110-3.

4. Ruchi Gupta, Saru Singh. Challenges in Paediatric Laparoscopic Surgeries. Indian Journal of Anaesthesia 2009; 53 (5):5605I6n6 .[PubMed] PMID: 20640106.

5. Bozkurt P, Kaya G, Yeker Y, et al. The cardiorespiratory effects of laparoscopic procedures in infants. Anaesthesia. 1999;54:831-4. [PubMed] PMID: 10460552.

6. Sunita goel. Anaesthesia for pediatric laparoscopy. AnestesiaPediatrica e Neonatale. 2006;4(N.1) http://www.anestesiarianimazione.com/20 06/01d.asp.

7. Jean JL. Anaesthesia for laparoscopic surgery. In: Roy CF, Edward Miller D, Gerald RJ, Michael RF, John SF, editors. Anaesthesia. 5th Edition. California: Churchill Livingstone; 2000. 2140-54.

8. Greg Hammer, Steven Hall, Peter J. Davis. Anesthesia for General Abdominal, Thoracic, Urologic and Bariatric Surgery. In: K.M.Etsuro and J.D.Peter editors. Smith's Anesthesia for Infants and Children, 7th Edition. Pennsylvania : mosbyelsevier. 2006: 686-88

9. Timothy BE. Anaesthesia for laparoscopic assisted surgery. In: Thomas HJ, Peter CJ, editors. A practice of anaesthesia. 6th Edition. London: Edward Arnold; 1995. 1391-96.

10. Lejus C, Delile L, Plattner V, et al: Randomized, single blinded trial of laparoscopic versus open appendectomy in children. Anaesthesiology. 84(4):8016.1996 DOI: $10.1097 / 00000542-$ 199604000-00006

11. Stez M, Guerard A, Desruelle P et al: Cardiorespiratory changes during laparoscopic fundoplication in children. PaediatrAnaesth 5: 89, 1995

12. Gloria Pelizzo, Aurora Puglisi, Marco Di M, et al: Laparoscopy in infants: Close intraoperative hemodynamic monitoring for patient safety. Journal of Pediatric Endoscopic Surgery; June 2019, Volume 1, Issue 1, 15-22. https://doi.org/10.1007/s42804-01900004-1.

13. Ganneedall P, Odeberg S, Brodin L-A et al : Effects of posture \& pneumo-peritoneum during anaesthesia on the indices of left ventricular filling.ActaAnaesthesiolScand 40:160,1996.

14. Hsing CH, Hseu SS, Tsai SK, et al: Study to determine the physiological effects of $\mathrm{CO} 2$ pneumo-peritoneum during laparoscopy in pediatric patients. Acta anaesthesiol Sin 1995 Mar; 33(1): 1-6. [PubMed : PMID: 7788192]

15. Sfez M, Guerard A, Desruelle et al:cardiorespiratory changes during laparoscopic fundoplication in children. Paediatric Anaesthesia 5.89,1995. [PubMed : PMID: 7489430]

16. Joris JL, Noirot DP, Legrand MJ, et al. Haemodynamic changes during laparoscopic cholecystectomy. Anaesth Analg 1993:76;1067-1071.

17. Odeberg S, Ljungqvist $\mathrm{O}$, Svenberg $\mathrm{T}$ et al. Haemodynamic effects of pneumoperitoneum and the influence of posture during anaesthesia for laparoscopic surgery. Acta AnaesthesiolScand 1994; 38: 276-83

18. Ishizaki Y, Bandai Y, Shimomura K, et al. Safe intra-abdominal pressure of carbon dioxide pneumo-peritoneum during 
laparoscopic surgery. Surgery. 1993; 114 (3):549-554.

19. Dexter SP, Vucevic M, Gibson J, et al. Haemodynamic consequences of high- and low-pressure capnoperitoneum during laparoscopic cholecystectomy. Surg Endosc. 1999;13(4):376-381.

20. R Sümpelmann, T. Schuerholz, G. Marx et al: Haemodynamic, acid-base and blood volume changes during prolonged low pressure pneumo-peritoneum in rabbits British Journal of Anaesthesia 2006 96(5):563-568. 